\title{
IMPACTS OF CLIMATE CHANGE ON THE TERRESTRIAL ECOSYSTEMS OF MADEIRA
}

\author{
M.J. CRUZ ${ }^{1}$, R. AGUIAR ${ }^{1}$, A. CORREIA ${ }^{2}$, T. TAVARES ${ }^{2}$, J.S. PEREIRA ${ }^{2}$ \& F.D. SANTOS 1 \\ ${ }^{1}$ CCIAM, Faculty of Sciences, University of Lisbon, Lisbon, Portugal. \\ ${ }^{2}$ Instituto Superior de Agronomia, Lisbon, Portugal.
}

\begin{abstract}
Climate change can have severe effects on the natural environment, including water resources and ecosystems. Islands are unique systems more vulnerable to climate change than continental areas. Madeira, an Atlantic subtropical island, has a quite unique flora and fauna and is considered a Mediterranean biodiversity 'hot-spot'. The lower altitudes of Madeira are predominantly occupied by urban areas and agricultural crops; exotic forest plantations are widespread at low- to mid-altitudes. The native forest, Laurissilva, an extremely important and rare ecosystem, occurs up to $1450 \mathrm{~m}$ and is replaced in higher altitudes by heaths and other altitude vegetation. The CLIMAAT project investigated the impact of climate change in Madeira ecosystems. Using global circulation models downscaled to Madeira, we produced climatic scenarios for 2040-2069 and 2070-2099. Subsequently, we generated future scenarios for hydrology, forest, agriculture, and biodiversity sectors. Future climatic scenarios project reduced rainfall and higher average temperatures across Madeira. The potentially suitable area for the main agricultural crops is expected to expand in altitude. Suitable area for the exotic forests and the Laurissilva is expected to increase as the expansion in altitude will be greater than the retraction in lower reaches. The suitable climatic range for heaths will suffer a severe reduction: it is expected to retract in lower reaches but cannot expand in altitude because it is predominantly in the higher elevations already. These shifts in habitat distributions may translate into large changes in ecosystem services supply. Altitude species, including endemic and rare ones, may suffer range reductions or even disappear. We discuss adaptation measures that should be taken into account in future conservation plans.
\end{abstract}

Keywords: ecosystems, global change, Madeira island, natural resources, vulnerability.

\section{INTRODUCTION}

Current climate change has already had effects on the natural environment, including agriculture, forestry, watercourses, and landscapes [1-3]. Much bigger changes, compared with what has occurred already, are projected for the twenty-first century [4-6]. The Intergovernmental Panel on Climate Change (IPCC) has placed considerable emphasis on the importance of regional and subregional assessments of climate change impacts, vulnerabilities, and adaptation measures.

Island environments are unique systems more vulnerable to climate change than continental areas [7]. Islands are highly dependent on their coastal areas and natural resources which are particularly vulnerable to climate change impacts [2]. Adaptation capacity is highly conditioned by geographic limitations and measures must be tailored to the island specificities. To our knowledge, there are no regional assessments of climate change impacts on Atlantic islands. Madeira Archipelago, together with the Canary islands, has been considered one of the Mediterranean 'hot-spots' for conservation of plant biodiversity [8].

In this paper, we present a regional assessment of climate change impacts on the terrestrial ecosystems of Madeira Archipelago. Future climatic scenarios with vulnerabilities of relevant sectors water resources, agriculture, forestry, and biodiversity - were integrated. We discuss adaptation measures of social-ecological systems in the context of sustainable development. 


\section{METHODS}

\subsection{Study area}

The Madeira Archipelago is located in the subtropical region of the Atlantic Ocean. Madeira, the main island of the Archipelago, has an area of $741 \mathrm{~km}^{2}$ and a population of 240,000 people. It has a steep topography with high mountains that reach more than $1800 \mathrm{~m}$ in altitude in the east. West from these formations there is a high plateau above $1400 \mathrm{~m}$. It presents a mild, thermally-stable weather all year through, except in the higher peaks that have lower temperatures (average annual temperatures range between 18 and $19^{\circ} \mathrm{C}$ in coastal areas and stand at $9^{\circ} \mathrm{C}$ on the mountain peak). Distribution of rain is highly controlled by topography with very wet high ground and drier coastal areas.

\subsection{Socio-economic scenarios}

The Special Report Emission Scenarios (SRES) of the IPCC [7] were used. SRES are a comprehensive set of narratives that define the local, regional, and global socio-economic driving forces of environmental change. The SRES storylines are structured in four major 'families' (A1, A2, B1, and B2) emphasizing a different set of social and economic development pathways. For a summary of the storylines, please see the IPCC reports $[2,7]$.

\subsection{Climatic scenarios}

Global circulation models (GCMs) cannot simulate the climate of small islands which is largely determined by its topographic and coastal features. Climatic scenarios for Madeira were obtained via downscaling of the GCM HadCM3, from the Hadley Centre for Climate Research. Downscaling was achieved with the CIELO model [9-11] with a resolution of $100 \mathrm{~m}$. CIELO simulates the climate by forcing an air mass with the meteorological characteristics corresponding to the nearest GCM grid point at sea level to ascend and descend the island topography. Daily data for the A2 and B2 GCMs were supplied by the LINK project [12]. The other scenarios were not used as daily data were not available. The periods defined for this study were: (a) 1961-1990 (control period), (b) 2040-2069, and (c) 2070-2099. The detailed methodology is described in a comprehensive report [13].

\subsection{Sectoral impact models}

We analyzed future scenarios for hydrology, forestry, agriculture, and biodiversity. The general approach was: (1) to establish a base case for each sector (i.e. present distribution or situation) researching available data (from the period 1970-1999), (2) to model the present (control) situation in relation to climatic factors, and (3) to generate future sectoral scenarios given the future climatic scenarios. Finally, we investigated possible interactions between different impacts (e.g. reduction in available water may be offset by bigger water demands for agriculture).

\subsection{Water resources}

Using the climatic scenarios obtained, we estimated monthly average rainfall and evapotranspiration. These were used as entry data for the hydrological Temez model [11], a simplification of the classic Standford Watershed model [14]. As output, the model produces runoff, aquifer recharge, and effective evapotranspiration monthly time series. Data from the Madeira hydrometric stations were used for validation. 


\subsection{Agriculture}

The island topography limits the agriculture which is essentially patchy, established in family smallholdings, and still uses traditional methods. It is mainly found in the south and east coasts where the weather is more favorable. Most agriculture uses irrigation, given the low rainfall in coastal areas.

We estimated changes in potential distribution for the three main agriculture products in Madeira: banana, wine, and potatoes. We obtained a model of the present distribution of these crops in relation to climatic factors and simulated future potential distributions for future climatic scenarios. Resulting maps are therefore of potential suitable areas for the crops. After plotting these areas, non-climatic limiting conditions were considered to remove areas from the potential suitable areas: gradient (above 20\%); natural or protected areas; rocky areas.

We estimated irrigation needs in future scenarios using the WIN ISAREG model [15], which simulates the soil water balance using data on crop and soil characteristics, rainfall, temperature, solar radiation, wind speed, and evapotranspiration.

\subsection{Forestry}

Madeira has both endemic woods and exotic plantations, namely, Pinus pinaster, Cryptomeria japonica, Pseudotsuga spp., Castanea sativa, Quercus spp., Acacia spp., and Eucalyptus spp. [16]. The lower altitudes of Madeira are predominantly occupied by urban areas and agricultural crops; exotic forest plantations are widespread at low- to mid-altitudes. The native humid forest, Laurissilva, an extremely important and rare ecosystem, occurs up to $1450 \mathrm{~m}$, and is replaced at higher altitudes by heath woodlands and other altitude vegetation. The endemic vegetation presently occupies over $20 \%$ of the island territory. Madeira encloses the largest area of Laurissilva woods in the world, which is biologically diverse from all other Laurissilva areas. It is still very well preserved, with some $90 \%$ of primary forest. It sustains a diverse biota and is very important for the ecological balance of the island. Native woods have been subjected to many stresses, namely, deforestation, fires, and introduction of exotic species [16].

We estimated changes in potential distribution for the three main woods in Madeira following the same procedure as for agriculture crops (see earlier). Fire risk was estimated with the SSR indicator which determines the daily fire risk during the 'fire season' [17]. We analyzed the number of days which fall in the 'extreme risk of fire' for all scenarios and calculated the frequency of consecutive days with maximum risk (which amplifies the probability of fires).

Productivity was estimated with the Biome-BGC model which has been used in several assessments of climate change impacts (e.g. Kang et al. [18]). Each biome is characterized by a set of ecophysiologic parameters which define the response of the plants to environmental factors. Given the lack of data on the Laurissilva species, we used the definition of evergreen tropical and subtropical forests. For the exotic species, mostly resinous, we used the parameters of P. pinaster.

\subsection{Biodiversity}

Madeira has a quite unique flora and fauna including many endemic species [19]. The lack of available sounding species data did not allow us to analyze specific responses to climate change. Since the biota are generally associated with the main habitats, our analyses of potential impacts focused on the analysis of impacts on the main habitats, that is, biodiversity impact assessment was considered as a function of the forestry analysis. 


\section{RESULTS}

\subsection{Climatic scenarios}

Projected average annual temperature is higher in both scenarios and in both study periods. The south coast will present the greater temperature increases. Both scenarios forecast reduced rainfall across Madeira, with no significant differences between A2 and B2. This reduction will be 5-30\% for 2040-2069 and 20-40\% for 2070-2099. The higher altitudes will suffer due to the greater rainfall reduction. Precipitation will be lower than in the control period in winter, spring, and autumn and higher in summer.

\subsection{Water resources}

Climate change will potentiate a severe reduction in water availability in Madeira. This tendency occurs for all seasons except summer. It is projected that the volume of available water annually will be reduced by $30 \%$ until 2050 and by $40-50 \%$ until 2100 . However, there is a high spatial variability in the projected scenarios.

\subsection{Agriculture}

All agriculture crops studied are expected to have more suitable area in future scenarios. For the A2 2070-2099, which has a bigger temperature increase, this tendency is greater. In general, future scenarios present a higher need of irrigation for the three crops. The exception is the 2040-2069 A2 scenario, where there is a lower average temperature, wind, and radiation, resulting in reduced evapotranspiration. Higher temperatures and atmospheric $\mathrm{CO}_{2}$ will potentiate greater productions of banana, wine, and potatoes (as long as the availability of nutrients in the soils is not a limiting factor) and more efficient water use [20]. This may contribute to a lower impact on irrigation demands. Magliulo et al. [21] showed an increase of $44 \%$ in potato production and a reduction of $11 \%$ in evapotranspiration when potato crops were fumigated with $\mathrm{CO}_{2}$. For the grapevines the increase in productivity will depend on the frequency of fogs and mists, not studied here. Finally, it should be noted that the quality of the wine produced in Madeira may change. The impacts of an increase in temperature will depend mostly on the varieties used and their temperature optimum and limits. Thus, it may be necessary to change varieties.

\subsection{Forestry}

Overall, fire risk is not expected to increase significantly. Estimates only project 'extreme fire risk' level in the south coast, an area essentially with agricultural and social occupation. All scenarios except the A2 for the 2040-2069 period show a greater number of days (and a greater frequency of consecutive days) with extreme risk of fire as compared to the control period. In the scenario A2 for 2040-2069, there is a small reduction in number of days with extreme risk of fire. This tendency to abandon agricultural fields, especially in steep areas where access is difficult and wood may accumulate, may increase fire risk.

The exotic forest can potentially expand in altitude in the 2040-2069 period in both scenarios (A2 and B2). For 2070-2099, this tendency is greater, especially in A2 where temperature is higher. For the lower altitudes reductions of the potential area are expected, although the uncertainties here are bigger, as these areas suffer a large human occupation. Moreover, there is a higher 
difficulty in simulating rainfall in these areas. All scenarios show a larger potential area for these forests. For the Laurissilva forest, and the 2040-2069 period there is a potential expansion for higher altitudes and a contraction in lower altitudes (although with larger uncertainties, see earlier; Fig. 1). In 2070-2099, the expansion in altitude reaches the higher peaks; the potential
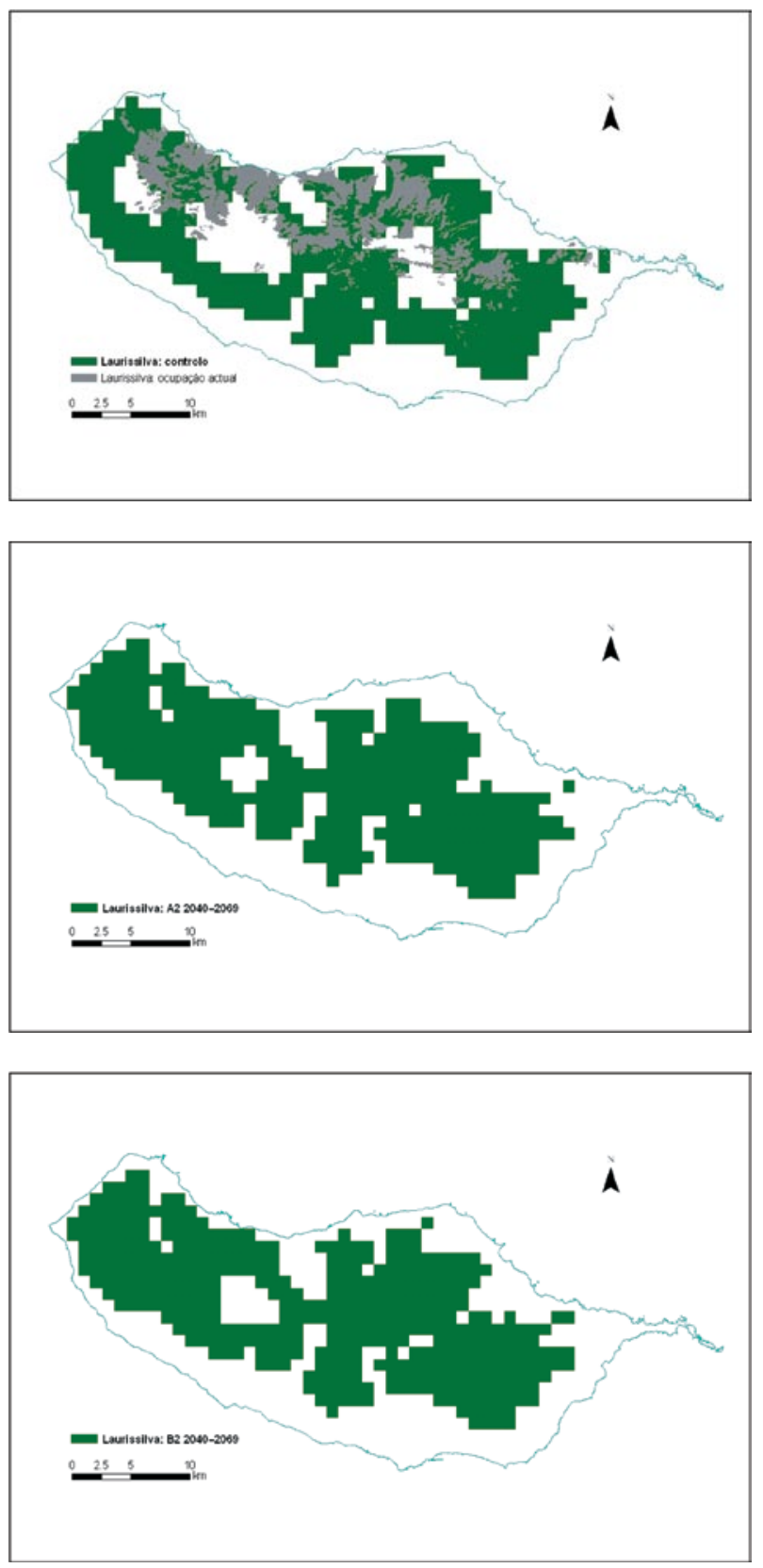

Figure 1: Potential area of Laurissilva forests in the control scenario and in future scenarios. 

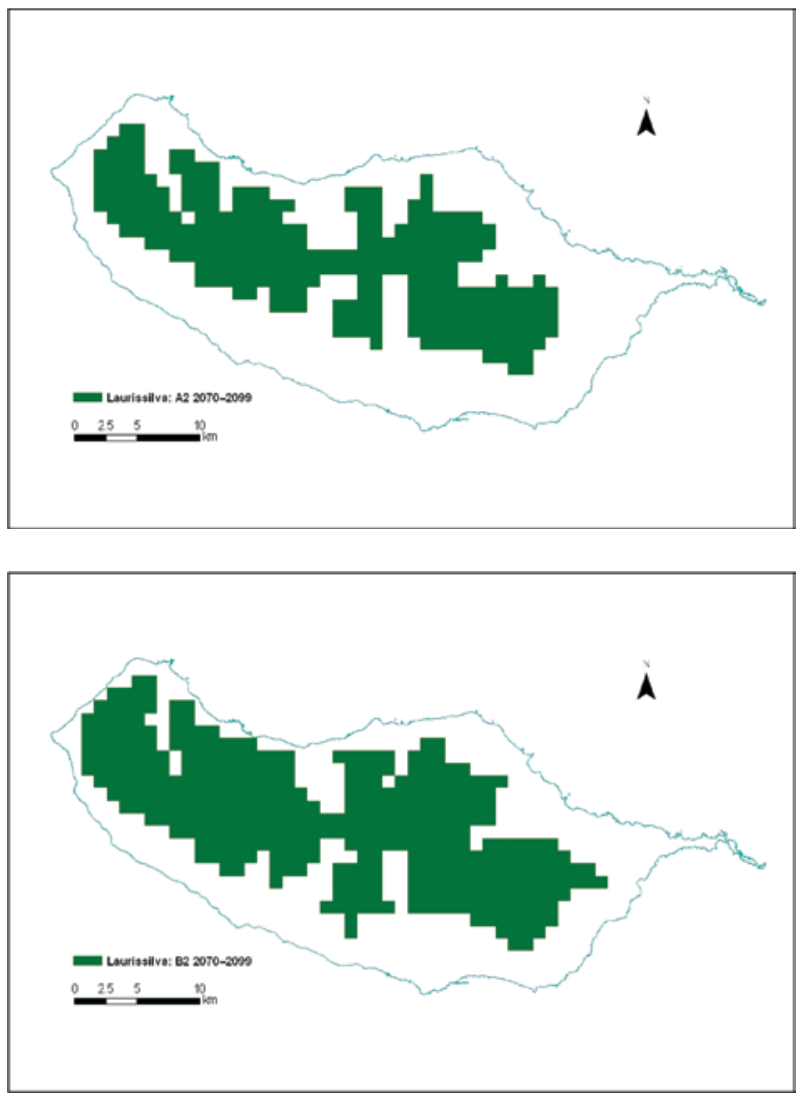

Figure 1: (Continued).

area in A2 is significantly smaller than in B2, reflecting A2 arid conditions. All scenarios show a larger potential area for this forest than at present. The evolution of the heaths distribution is similar to the other forests, with an expansion in altitude and a reduction in lower reaches. However, since these woods are predominantly in the higher altitudes already, they will suffer a severe reduction (Fig. 2).

An increase in productivity is expected for both Laurissilva and exotic woods in areas above 600-700 m. For lower altitudes, the low rainfall produced by the CIELO model does not allow for conclusive results. Increases in productivity may be limited by availability of soil nutrients.

\subsection{Biodiversity}

Heaths and other altitude vegetation will suffer a decrease in suitable area and in the long run may be completely replaced. Biota associated with this vegetation may suffer similar decreases in suitable area and endemic and rare species may disappear. On the other hand, Laurissilva forests and associated biota may suffer a positive impact from climate change. Future studies should focus on species responses to climate change and potential shifts in habitats. Climate change may also generate phenological or physiological responses in species. 

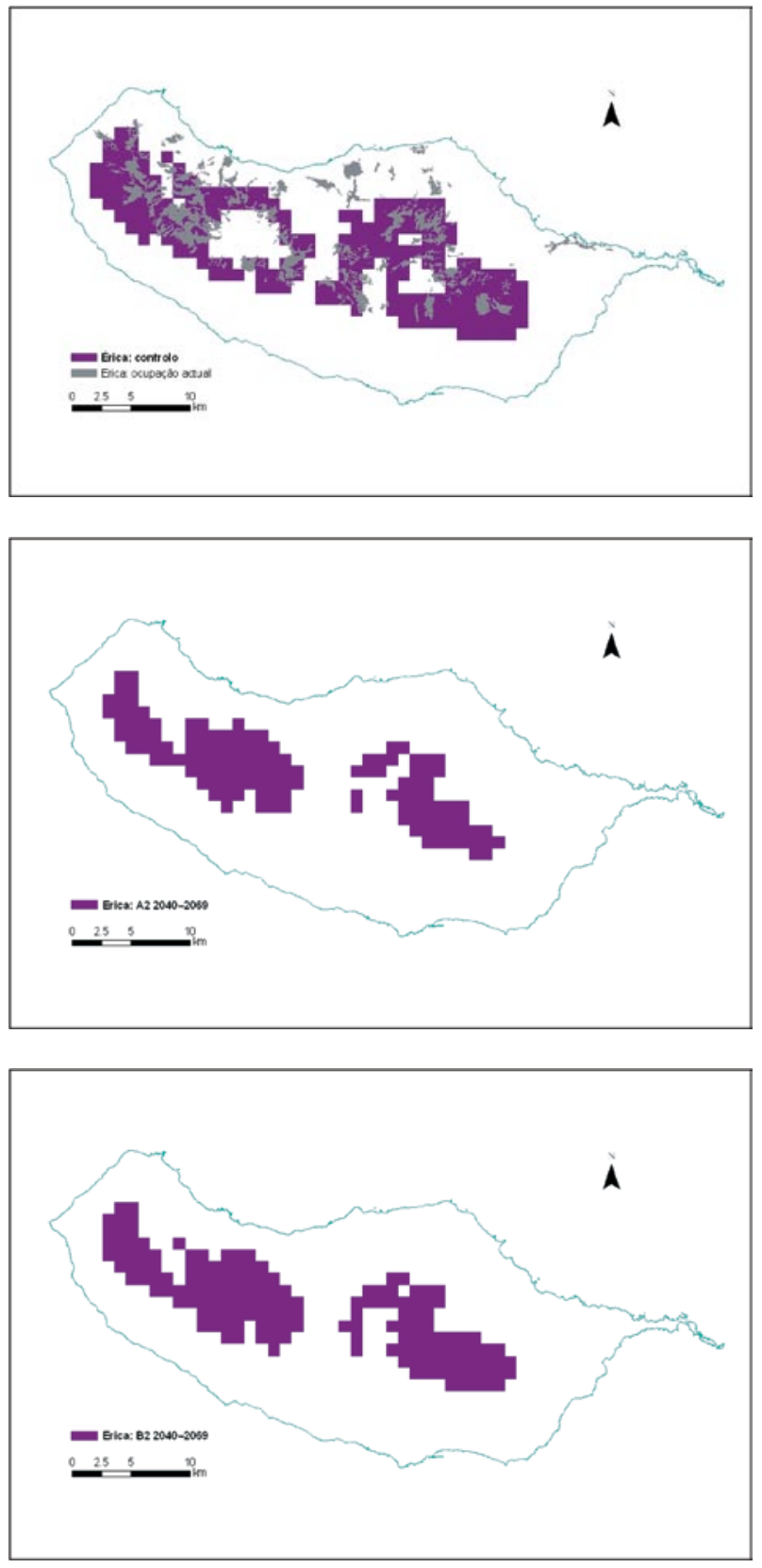

Figure 2: Potential area of heath woodlands in the control scenario and in future scenarios. 

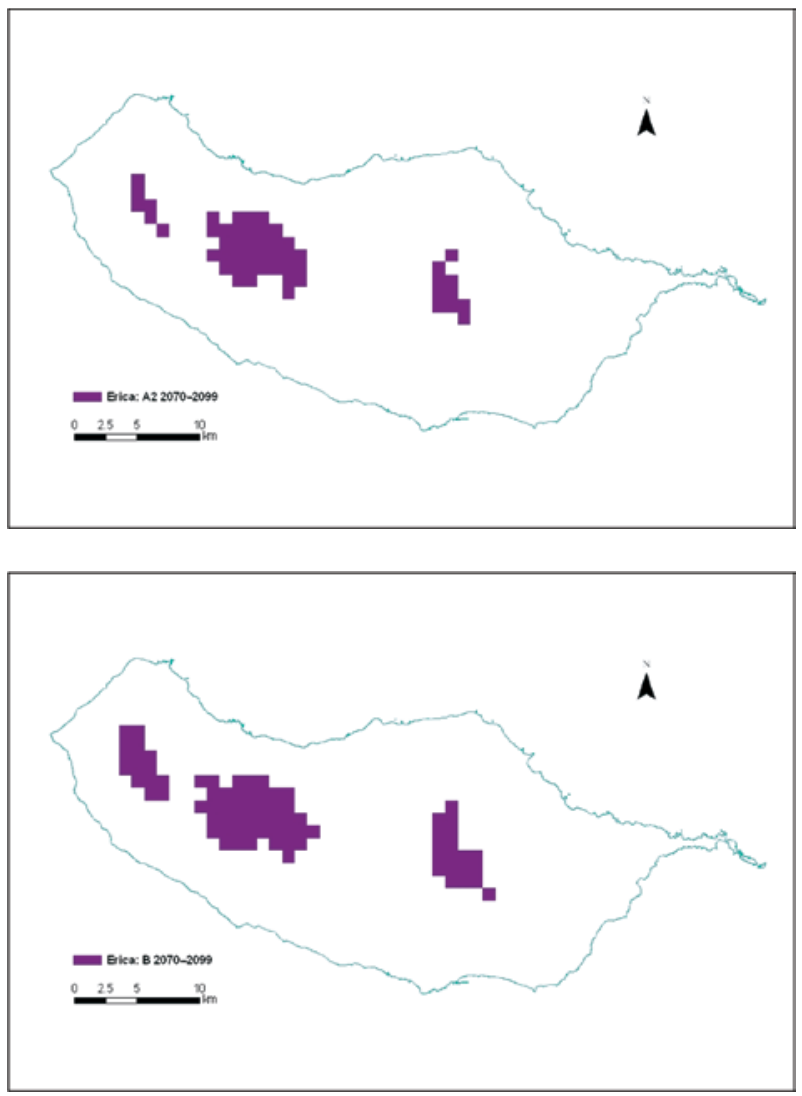

Figure 2: (Continued).

\section{CONCLUSIONS}

Climate change will pose a serious challenge to the management of Madeira water resources. Capacity of present infrastructures to guarantee future water needs will be compromised by lower rainfall, increased evapotranspiration, and higher water demands for irrigation. A pro-active water management system is needed, based on rationalization of water use and adaptation of hydrologic systems. It will be critical to: (1) have a better evaluation of the water resources, (2) put in place good monitoring schemes, and (3) produce additional studies on climate change effects and its interactions (e.g. water needs in future scenarios).

The expected changes in agriculture, forests, and biodiversity can significantly modify the economic and aesthetic resources of Madeira. Climate change will affect climatic ranges of crops and forests and alternative land use options may arise. We studied suitable climatic areas for the projected climate change. However, distributional changes will depend on management practices.

Agriculture and forests may play an extremely important role in adaptation to climate change. Agriculture options (e.g. crops and varieties used) may be adjusted to achieve reduced water needs alongside increased agricultural production. Forests can greatly contribute to water catchments and preservation and to the regulation of the hydrological cycle. Adaptation of the agricultural sector to climate change can be divided into four main areas: (1) knowledge strengthening, (2) agronomic 
developments (including adjusting crops, varieties, and dates for plantation, irrigation, etc. to expected climatic conditions), (3) technological developments (e.g. for water efficiency use), and (4) financial/economic measures.

Unlike in agriculture, adaptation measures for forests need to be planned well in advance because of the long life-span of trees. There is critical lack of knowledge regarding forests distribution, species characterization, production, and functioning and services of ecosystems. We need to further investigate Laurissilva ecosystems and reconvert abandoned agricultural fields into forests. Wood production should be mainly of native species; exotic species should follow a rigorous selection. Finally, a program to prevent fires in the most susceptible areas should be put in place.

The endemic species of Madeira are limited to particular habitats and some of these are already under serious threat due to agriculture activities, urbanization, and invasive species [19] and climate change may interact with these stressors. For example, island biota is extremely vulnerable to invasion and displacement by non-native plants and animals and climate change is expected to exacerbate the impacts of invasions [1]. Indirect effects such as the occurrence of climatic extremes such as droughts may also deeply change vegetation dynamics [22]. Much of the future of biodiversity will depend on planned adaptation on other sectors (e.g. agriculture, forests, coastal zones). Conservation goals and policies need to be revised in order to consider potential climate change impacts on biodiversity and on natural resources. The limits of protected areas need to be revised to take account of future climatic ranges of habitats. Finally, conservation priorities need to be established in light of long term sustainability. Conservation of Madeira biodiversity will require a serious and prompt commitment from land management agents and politicians.

\section{REFERENCES}

[1] Lovejoy, T.E. \& Hannah, L., Climate Change and Biodiversity. Yale University Press: New Haven and London, 2005.

[2] IPCC. IPCC Fourth Assessment Report (AR4), eds R.T. Watson \& Core Writing Team, Geneva, Switzerland, 2007.

[3] EEA, JRC \& WHO. Impacts of Europe's Changing Climate - 2008 Indicator-based Assessment, European Environment Agency: Copenhagen, 2008.

[4] Rogers, C.E. \& McCarty, J.P., Climate change and ecosystems of the mid-Atlantic region. Climate Research, 14, pp. 235-244, 2000. doi:10.3354/cr014235; doi:10.1016/S0217-9849(00)00034-3

[5] Thomas, C.D., Cameron, A., Green, R.E., Bakkenes, M., Beaumont, L.J., Collingham, Y.C., Erasmus, B.F.N., Ferreira de Siquiera, M., Grainger, A., Hannah, L., Hughes, L., Huntley, B., van Jaarseveld, A.S., Midgley, G.F., Miles, L., Ortega-Huerta, M.A., Peterson, A.T., Phillips, O.L. \& Williams, S.E., Extinction risk from climate change. Nature, 427, pp. 145-148, 2004. doi:10.1038/nature02121

[6] Metzger, M.J., Schroter, D., Leemans, R. \& Cramer, W., A spatially explicit and quantitative vulnerability assessment of ecosystem service change in Europe. Reg Environ Change, 8(3), pp. 91-107, 2008. doi:10.1007/s10113-008-0044-x

[7] IPCC. Climate Change 2001: Impacts, Adaptation and Vulnerability. Contribution of Working Group II to the IPCC Third Assessment Report. Geneva, Switzerland, 2001.

[8] Medail, F. \& Quezel, P., Hot-spots analysis for conservation of plant biodiversity in the Mediterranean basin. Annals of the Missouri Botanical Garden, 84, pp. 112-127, 1997. doi: $10.2307 / 2399957$

[9] Azevedo, E.B., Pereira, L.S. \& Itier, B., Modeling the local Climate in island environments: water balance applications. Agricultural Water Management, 40, pp. 393-403, 1999. doi:10.1016/S0378-3774(99)00012-8 
[10] Santos, F.D., Valente, M.A., Miranda, P.M., Aguiar, A., Azevedo, E.B., Tomé, A.R. \& Coelho, F., Climate change scenarios in the Azores and Madeira Islands. World Resource Review, 16(4), pp. 473-491, 2004.

[11] SIAM. Climate Change in Portugal: Scenarios, Impacts and Adaptation Measures, eds F. Santos, K. Forbes \& Moita, Gradiva: Lisboa, 2002.

[12] Viner, D. The climate impacts LINK project. Climate Monitor, 23(3-5), 1996.

[13] CLIMAAT, Impactos e medidas de adaptação às alterações climáticas na ilha da Madeira, eds F.D. Santos \& R. Aguiar, Portugal, 2006.

[14] Linsley, R.K. \& Crawford, N.H., Computation of a synthetic streamflow record on a digital computer. International Association of Scientific Hydrology, 5, pp. 526-538, 1960.

[15] Teixeira, J.L., Manual Do Programa Isareg (Versão w1.1) in http://www.isa.utl.pt/der/Eng Arquitectura/programa_isareg.htm 2006.

[16] Capelo, J., Sequeira, M., Jardim, R., Mesquita, S. \& Costa, J.C., The vegetation of Madeira Island (Portugal) - a brief overview and excursion guide. Quercetea, 7, pp. 95-122, 2005.

[17] Durão, R.M., Soares, A., Pereira, J.M.C., Corte-Real, J.A. \& Coelho, M.F. Bayesian Classification of a Meteorological Risk Index for Forest Fires: DSR. geoENV VI-Geostatistics for Environmental Applications, 15, pp. 283-294, 2009

[18] Kang, S., Kimball, J.S. \& Running, S.W., Simulating effects of fire disturbance and climate change on boreal forest productivity and evapotranspiration. Science of The Total Environment, 362(1), pp. 85-102, 2006. doi:10.1016/j.scitotenv.2005.11.014

[19] Borges, P.A.V., Abreu, C., Aguiar, A.M.F., Carvalho, P., Fontinha, S., Jardim, R., Melo, I., Oliveira, P., Serrano, A.R.M. \& Vieira, P., A List of the Terrestrial Fungi, Flora and Fauna of Madeira and Selvagens Archipelago. Direcção Regional do Ambiente da Madeira \& Universidade dos Açores, Funchal e Angra do Heroísmo, 2008.

[20] Cannon, R.J.C., The implications of predicted climate change for insect pests in the UK, with emphasis on non-indigenous species. Global Change Biology, 4, pp. 785-796, 1998. doi:10.1046/j.1365-2486.1998.00190.x

[21] Magliulo, V., Bindi, M. \& Ranac, G., Water use of irrigated potato (Solanum tuberosum L.) grown under free air carbon dioxide enrichment in central Italy. Agriculture, Ecosystems and Environment, 97, pp. 65-80, 2003. doi:10.1016/S0167-8809(03)00135-X

[22] Pereira, J.S., Chaves, M.M., Caldeira, M.C. \& Correia, A.V., Water availability and productivity. Plant Growth and Climate Change, eds J.I.L. Morison \& M.D. Morecroft, Blackwells: London, pp. 118-145, 2006. doi:10.1002/9780470988695.ch6 